\title{
Risk of cancer among patients with herpes zoster infection: a population-based study
}

\author{
Yu-Ping Wang MD, Chia-Jen Liu MD, Yu-Wen Hu MD, Tzeng-Ji Chen MD, Yi-Tsung Lin MD, \\ Chang-Phone Fung MD
}

Competing interests: None declared.

This article has been peer reviewed.

Correspondence to: Yi-Tsung Lin, ytlin8@vghtpe.gov.tw

CMAJ 2012. DOI:10.1503 /cmaj.120518

\begin{abstract}
Background: Whether the risk of cancer is increased among patients with herpes zoster is unclear. We investigated the risk of cancer among patients with herpes zoster using a nationwide health registry in Taiwan.
\end{abstract}

Methods: We identified 35871 patients with newly diagnosed herpes zoster during 2000-2008 from the National Health Insurance Research Database in Taiwan. We analyzed the standardized incidence ratios for various types of cancer.

Results: Among patients with herpes zoster, 895 cases of cancer were reported. Patients erpes zoster, or shingles, is caused by reactivation of the varicella-zoster virus, a member of the Herpesviridae family. Established risk factors for herpes zoster include older age, chronic kidney disease, malignant disease and immunocompromised conditions (e.g., those experienced by patients with AIDS, transplant recipients, and those taking immunosuppressive medication because of autoimmune diseases).$^{1-5}$ Herpes zoster occurs more frequently among patients with cancer than among those without cancer; ${ }^{6,7}$ however the relation between herpes zoster and risk of subsequent cancer is not well established.

In 1955, Wyburn-Mason and colleagues reported several cases of skin cancer that arose from the healed lesions of herpes zoster. ${ }^{8}$ In 1972, a retrospective cohort study and a case series reported a higher prevalence of herpes zoster among patients with cancer, especially hematological cancer; ${ }^{6,7}$ however, they did not investigate whether herpes zoster was a risk factor for cancer. In 1982, Ragozzino and colleagues found no increased incidence of cancer (including hematologic malignancy) among patients with herpes zoster. ${ }^{9}$ There have been reports of significantly increased risk of some with herpes zoster were not at increased risk of cancer (standardized incidence ratio 0.99, $95 \%$ confidence interval 0.93-1.06). Among the subgroups stratified by sex, age and years of follow-up, there was also no increased risk of overall cancer.

Interpretation: Herpes zoster is not associated with increased risk of cancer in the general population. These findings do not support extensive investigations for occult cancer or enhanced surveillance for cancer in patients with herpes zoster. subtypes of cancer among patients aged more than 65 years with herpes zoster ${ }^{10}$ and among those admitted to hospital because of herpes zoster. ${ }^{11}$ Although these studies have suggested an association between herpes zoster and subsequent cancer, their results might not be generalizable because of differences in the severity of herpes zoster in the enrolled patients.

Whether the risk of cancer is increased after herpes zoster remains controversial. The published studies ${ }^{8-11}$ were nearly all conducted in western countries, and data focusing on Asian populations are lacking. ${ }^{12}$ The results from western countries may not be directly generalizable to other ethnic groups because of differences in cancer types and profiles. Recently, a study reported that herpes zoster ophthalmicus may be a marker of increased risk of cancer in the following year. ${ }^{13}$ In the present study, we investigated the incidence rate ratio of cancer, including specific types of cancer, after diagnosis of herpes zoster.

\section{Methods}

\section{Data sources}

We used data from the National Health Insurance Research Database released by the National 
Health Research Institute in Taiwan. The National Health Insurance program finances health care for $99 \%$ of all of residents of Taiwan (> 25 million enrollees). This database includes comprehensive information about insured people, including demographic data, dates of clinical visits, diagnostic codes, details of prescriptions, expenditure levels and dates of enrolment and withdrawal between January 1996 and December 2008. Using a systematic sampling method for research purposes, the National Health Research Institute randomly sampled a representative database of 1000000 patients enrolled in the National Health Insurance program in the year 2000. There were no statistically significant differences in age, sex or health care costs between the sampled group and all enrollees, as reported by the National Health Research Institute. ${ }^{14}$

To help ensure the precision of the claims data, the Bureau of National Health Insurance performs quarterly expert reviews on random samples of every 50-100 ambulatory and inpatient claims for each hospital and clinic. The claims data are generally accurate and have been extensively used in epidemiologic studies published in peer-reviewed journals..$^{15-19}$

The International Classification of Diseases 9th revision (ICD-9) codes were used during the study period. Personal information, including family history of cancer, lifestyle factors and habits (e.g., smoking, alcohol use), were not available from the National Health Insurance Research Database. The dataset used in this study consists of de-identified secondary data released to the public for research purposes.

This study was approved by the institutional review board of Taipei Veterans General Hospital.

\section{Study population}

We conducted a retrospective cohort study from Jan. 1, 1996, to Dec. 31, 2008. Patients who were admitted to hospital or visited an ambulatory care clinic with a primary diagnosis of herpes zoster (ICD-9 clinical modification [ICD-9CM] codes 053-053.9) for the first time between Jan. 1, 2000, and Dec. 31, 2008, were included. We excluded patients with a diagnosis of herpes zoster between Jan. 1, 1996, and Dec. 31, 1999.

We identified 41888 patients with newly diagnosed herpes zoster infection during the study period. We excluded patients under the age of 20 years $(n=4626)$ or with cancer before the diagnosis of herpes zoster $(n=1391)$. The final cohort included 35871 patients.

\section{Identification of cancer cases}

Each patient in the study was tracked through the National Health Insurance Research Database from the diagnosis of herpes zoster to identify whether the patient received a cancer diagnosis. We identified cancer diagnoses using records from the Catastrophic Illness Patient Database, a subset of the National Health Insurance Research Database. In Taiwan, patients with cancer apply for a catastrophic illness certificate so that they do not have to pay any out-of-pocket expenses for their cancer evaluation and care. The application requires histologic confirmation and supporting evidence, such as additional laboratory and imaging studies, including tumour marker

\begin{tabular}{|lrl|}
\hline $\begin{array}{l}\text { Table 1: Characteristics of patients with herpes } \\
\text { zoster }\end{array}$ & & \\
\hline Characteristic & No. (\%) \\
\hline Sex & & \\
\hline Male & 16801 & $(46.8)$ \\
\hline Female & 19070 & $(53.2)$ \\
\hline Age & & \\
\hline $20-39$ & 9533 & $(26.6)$ \\
\hline $40-59$ & 14309 & $(39.9)$ \\
\hline$\geq 60$ & 12029 & $(33.5)$ \\
\hline Comorbidity & & \\
\hline Diabetes mellitus & 6615 & $(18.4)$ \\
\hline Chronic renal failure & 2796 & $(7.8)$ \\
\hline Autoimmune diseases & 1768 & $(4.9)$ \\
\hline Chronic pulmonary disease & 11818 & $(32.9)$ \\
\hline Liver cirrhosis & 607 & $(1.7)$ \\
\hline Congestive heart failure & 2056 & $(5.7)$ \\
\hline Cerebrovascular disease & 4459 & $(12.4)$ \\
\hline
\end{tabular}

Table 2: Standardized incidence ratios for cancer in patients with herpes zoster, by age, sex and duration of follow-up

\begin{tabular}{|lccc|}
\hline Characteristic & $\begin{array}{c}\text { No. of cancers } \\
\text { observed }\end{array}$ & $\begin{array}{c}\text { No. of cancers } \\
\text { expected }\end{array}$ & $\begin{array}{c}\text { Standardized } \\
\text { incidence ratio } \\
(95 \% \mathrm{Cl})\end{array}$ \\
\hline All patients & 895 & 905.38 & $0.99(0.93-1.06)$ \\
\hline Male & 513 & 498.19 & $1.03(0.94-1.12)$ \\
\hline Female & 382 & 407.19 & $0.94(0.85-1.04)$ \\
\hline Age, yr & & & \\
\hline $20-39$ & 245 & 238.93 & $1.01(0.66-1.47)$ \\
\hline $40-59$ & 491 & 502.86 & $0.98(0.89-1.07)$ \\
\hline $60-79$ & 132 & 136.81 & $0.96(0.81-1.14)$ \\
\hline$\geq 80$ & & & $0.91(0.78-1.05)$ \\
\hline Follow-up, yr & 181 & 199.33 & $0.99(0.91-1.08)$ \\
\hline$\leq 1$ & 537 & 541.47 & $1.08(0.92-1.25)$ \\
\hline $1-5$ & 177 & 164.58 & \\
\hline$>5$ & & & \\
\hline Note: Cl = confidence interval. & & \\
\hline
\end{tabular}


surveys, radiographs, bone scans, computed tomography or magnetic resonance imaging. Applications are formally reviewed and approved by the Bureau of National Health Insurance. Only patients who meet the diagnostic criteria are issued a certificate. The diagnostic codes of malignancies were defined as ICD-9CM 140-208. All cancer patients were also enrolled in the Taiwan Cancer Registry.

\section{Statistical analysis}

All enrolled patients were followed until a diagnosis of cancer, death, dropout from the National Health Insurance program or the end of 2008. We estimated the risk of cancer among the study cohort using standardized incidence ratios, which is the number of cancer cases among patients with herpes zoster divided by the expected number of cases. We calculated the expected number by mul-

\begin{tabular}{|c|c|c|c|}
\hline Characteristic & $\begin{array}{l}\text { No. of } \\
\text { cancers } \\
\text { observed }\end{array}$ & $\begin{array}{c}\text { No. of } \\
\text { cancers } \\
\text { expected }\end{array}$ & $\begin{array}{c}\text { Standardized } \\
\text { incidence ratio } \\
(95 \% \mathrm{Cl})\end{array}$ \\
\hline All cancers & 895 & 905.38 & $0.99(0.93-1.06)$ \\
\hline Head and neck & 69 & 71.91 & $0.96(0.75-1.21)$ \\
\hline Digestive & 326 & 360.33 & $0.900 .81-1.01)$ \\
\hline Esophagus & 11 & 18.03 & $0.61(0.30-1.09)$ \\
\hline Stomach & 47 & 49.88 & $0.94(0.69-1.25)$ \\
\hline Colon and rectum & 136 & 138.40 & $0.98(0.82-1.16)$ \\
\hline Liver and biliary tract & 117 & 136.91 & $0.85(0.71-1.02)$ \\
\hline Pancreas & 15 & 17.10 & $0.880 .49-1.45)$ \\
\hline Lung and mediastinum & 130 & 119.05 & $1.09(0.91-1.30)$ \\
\hline Bone and soft tissue & 14 & 6.88 & $2.03(1.11-3.41)$ \\
\hline Skin & 20 & 18.57 & $1.08(0.66-1.66)$ \\
\hline Breast & 68 & 83.24 & $0.82(0.63-1.04)$ \\
\hline Genitourinary & 171 & 156.01 & $1.10(0.94-1.27)$ \\
\hline Cervix & 18 & 26.96 & $0.67(0.40-1.06)$ \\
\hline Uterus & 15 & 12.35 & $1.22(0.68-2.00)$ \\
\hline Ovary & 8 & 11.01 & $0.73(0.31-1.43)$ \\
\hline Prostate & 63 & 48.78 & $1.29(0.99-1.65)$ \\
\hline Bladder & 40 & 32.51 & $1.23(0.88-1.68)$ \\
\hline Kidney & 27 & 24.41 & $1.11(0.73-1.61)$ \\
\hline Thyroid & 17 & 15.25 & $1.12(0.65-1.79)$ \\
\hline Hematologic & 45 & 38.70 & $1.16(0.85-1.56)$ \\
\hline Non-Hodgkin lymphoma & 25 & 19.56 & $1.28(0.83-1.89)$ \\
\hline Hodgkin disease & 1 & 0.76 & $1.31(0.03-7.31)$ \\
\hline Multiple myeloma & 11 & 5.42 & $2.03(1.01-3.63)$ \\
\hline Leukemia & 8 & 12.96 & $0.62(0.27-1.22)$ \\
\hline Others & 35 & 35.45 & $0.99(0.69-1.37)$ \\
\hline \multicolumn{4}{|l|}{ Note: $\mathrm{Cl}=$ confidence interval. } \\
\hline
\end{tabular}

tiplying the national incidence rate of cancer according to sex, age (in 5-yr intervals) and calendar year (each yr) by the corresponding stratumspecific person-time accrued in the cohort. The data for national incidence rates of cancer were obtained from the Taiwan Cancer Registry. The 95\% confidence intervals (CIs) for the standardized incidence ratios were estimated under the assumption that the observed number of cancer cases followed a Poisson probability distribution. We determined the standardized incidence ratios for the subgroups according to age, sex and years of follow-up. We defined statistical significance as $p<0.05$.

\section{Results}

\section{Study population}

We included 35871 patients with newly diagnosed herpes zoster in the study. Patients were between 20 and 101 years, and the median age was 52 years. Patient demographic and comorbidity data are shown in Table 1 . Most patients were aged 60 years or younger $(66.5 \%)$, and there was a greater percentage of women $(53.2 \%)$ than men. Chronic pulmonary diseases $(32.9 \%)$, diabetes mellitus (18.4\%) and cerebrovascular disease $(12.4 \%)$ were the most common underlying diseases in the cohort. The median follow-up time was 3.68 years (interquartile range 1.72$5.98 \mathrm{yr})$.

\section{Risk of cancer}

During the observation period of 140905.83 person-years, 1151 patients were lost to followup, 938 patients died, and 895 cancers were identified after the diagnosis of herpes zoster. There was no increased risk of cancer among patients with herpes zoster compared with the general population (standardized incidence ratio 0.99, 95\% CI 0.93-1.06). Among the subgroups stratified by sex, age and years of follow-up, there was also no increased risk of cancer (Table 2).

There was no increased risk of most types of cancer, including skin cancer (standardized incidence ratio 1.08 , 95\% CI 0.66-1.66) (Table 3). There was an increased risk of multiple myeloma (standardized incidence ratio 2.03, 95\% CI 1.01-3.63) and bone and soft-tissue cancer (standardized incidence ratio $2.03,95 \%$ CI 1.11-3.41). Further subgroup analysis of multiple myeloma and bone and soft-tissue cancer is shown in Table 4 and Table 5. The increased risk of multiple myeloma was not observed among men. Women (standardized incidence ratio 2.97, 95\% CI 1.19-6.12) aged 60-79 years (standardized incidence ratio $3.31,95 \%$ CI 1.07-7.71) and followed for 1-5 years after herpes zoster diag- 
Table 4: Standardized incidence ratios for multiple myeloma in patients with herpes zoster, by age, sex and duration of follow-up

\begin{tabular}{|c|c|c|c|c|c|c|c|c|}
\hline \multicolumn{3}{|c|}{ Total } & \multicolumn{3}{|c|}{ Men } & \multicolumn{3}{|c|}{ Women } \\
\hline $\begin{array}{c}\text { No. } \\
\text { observed }\end{array}$ & $\begin{array}{c}\text { No. } \\
\text { expected }\end{array}$ & $\begin{array}{l}\text { Standardized } \\
\text { incidence ratio } \\
(95 \% \mathrm{Cl})\end{array}$ & $\begin{array}{c}\text { No. } \\
\text { observed }\end{array}$ & $\begin{array}{c}\text { No. } \\
\text { expected }\end{array}$ & $\begin{array}{c}\text { Standardized } \\
\text { incidence ratio } \\
(95 \% \mathrm{Cl})\end{array}$ & $\begin{array}{c}\text { No. } \\
\text { observed }\end{array}$ & $\begin{array}{c}\text { No. } \\
\text { expected }\end{array}$ & $\begin{array}{c}\text { Standardized } \\
\text { incidence ratio } \\
(95 \% \mathrm{Cl})\end{array}$ \\
\hline 11 & 5.42 & $\begin{array}{c}2.03 \\
(1.01-3.63)\end{array}$ & 4 & 3.06 & $\begin{array}{c}1.31 \\
(0.36-3.34)\end{array}$ & 7 & 2.36 & $\begin{array}{c}2.97 \\
(1.19-6.12)\end{array}$ \\
\hline
\end{tabular}

\begin{tabular}{cccccccccccc}
$20-39$ & 0 & 0.02 & $\begin{array}{c}0.00 \\
(0.00-152.43)\end{array}$ & 0 & 0.01 & $\begin{array}{c}0.00 \\
(0.00-256.92)\end{array}$ & 0 & 0.01 & $(0.00-374.81)$ \\
$40-59$ & 1 & 0.99 & $\begin{array}{c}1.01 \\
(0.03-5.62)\end{array}$ & 0 & 0.51 & $\begin{array}{c}0.00 \\
(0.00-7.28)\end{array}$ & 1 & 0.48 & $(0.05-11.50)$ \\
\hline $60-79$ & 8 & 3.51 & $\begin{array}{c}2.28 \\
(0.98-4.49)\end{array}$ & 3 & 2.00 & $\begin{array}{c}1.50 \\
(0.31-4.39)\end{array}$ & 5 & 1.51 & $\begin{array}{c}3.31 \\
(1.07-7.71)\end{array}$ \\
$\geq 80$ & 2 & 0.89 & $\begin{array}{c}2.24 \\
(0.27-8.07)\end{array}$ & 1 & 0.54 & $(0.05-10.24)$ & 1 & 0.35 & $(0.07-15.88)$
\end{tabular}

Follow-up, yr

\begin{tabular}{ccccccccccc}
$\leq 1$ & 3 & 1.18 & $\begin{array}{c}2.55 \\
(0.52-7.44)\end{array}$ & 2 & 0.67 & $\begin{array}{c}2.98 \\
(0.36-10.77)\end{array}$ & 1 & 0.51 & $(0.05-10.98)$ \\
\hline $1-5$ & 6 & 3.24 & $\begin{array}{c}1.85 \\
(0.68-4.03)\end{array}$ & 1 & 1.82 & $\begin{array}{c}0.55 \\
(0.01-3.05)\end{array}$ & 5 & 1.41 & $(1.15-8.26)$ \\
\hline 5 & 2 & 1.01 & $\begin{array}{c}1.99 \\
(0.24-7.19)\end{array}$ & 1 & 0.57 & $(0.04-9.81)$ & 1 & 0.44 & $(0.06-12.74)$
\end{tabular}

Note: $\mathrm{Cl}=$ confidence interval.

Table 5: Standardized incidence ratios for bone and soft-tissue cancer in patients with herpes zoster, by age, sex and duration of follow-up

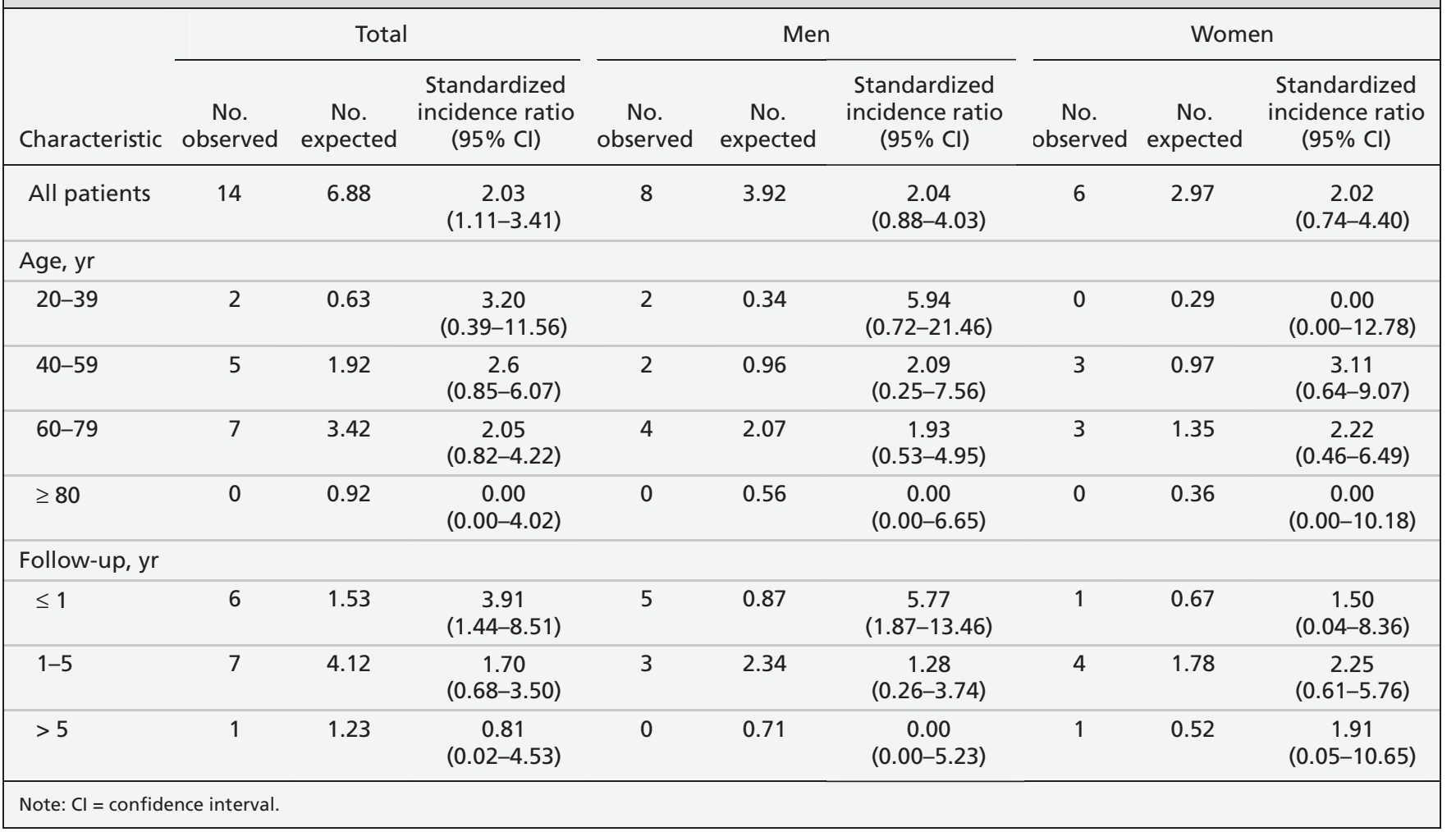


nosis (standardized incidence ratio $3.54,95 \% \mathrm{CI}$ 1.15-8.26) had an increased risk of multiple myeloma. The increased risks of bone and softtissue cancer were observed only among men followed within the first year after diagnosis of herpes zoster (standardized incidence ratio 5.77, 95\% CI 1.87-13.46).

\section{Interpretation}

We found no overall increased risk of cancer among patients with herpes zoster compared with the general population, regardless of sex, age or years of follow-up. We found an increased risk of only multiple myeloma and bone and soft-tissue cancer among these patients. However, we should acknowledge that multiple testing may somewhat account for the apparent associations in these subgroups.

In published cohort studies there are no consistent data to indicate whether herpes zoster increases the risk of cancer. In 1982, Ragozzino and colleagues ${ }^{9}$ published the first populationbased cohort study to evaluate the risk of cancer after diagnosis of herpes zoster. They followed 590 people in Minnesota for 9389 person-years after diagnosis of herpes zoster and found that the overall relative risk of cancer was insignificant (relative risk 1.1, 95\% CI 0.9-1.3). They did, however, report an increased risk of colon and bladder cancer among women, but no increased risk of hematologic malignancy.

Sørensen and colleagues ${ }^{11}$ examined the data for 10588 patients admitted to hospital between 1977 and 1996 because of herpes zoster for subsequent risk of cancer. The relative risk of all types of cancer was 1.3 in the first year $(95 \% \mathrm{CI}$ 1.1-1.5), but the relative risk of hematologic cancer in the first year was 3.4 (95\% CI 2.3-4.9). Buntinx and colleagues ${ }^{10}$ examined the emergence of subsequent cancer in patients $(311000$ patient-years) with and without herpes zoster in Belgium from 1994 to 2000. They found that, after adjustment for age and sex, there was a significant increase in cancer among women aged 65 or more years. Both of the studies focused on specific groups instead of the general population.

Our findings are compatible with those from a study published in 1982, ${ }^{9}$ but differ from 2 more recent studies. ${ }^{10,11}$ It is possible that the differences in findings are because of the more advanced diagnostic tools now available for the detection of occult malignancy. Our data are from a time (2000-2008) when advances in diagnostic technology enabled earlier and more reliable detection of cancer than in previous studies; however, we did not find an increased overall risk of cancer among patients with herpes zoster. In contrast to the previous studies conducted in western countries, almost all residents in Taiwan are of Han Chinese ethnic background. The genetic susceptibility to or geographic differences in the incidence cancer may explain the heterogeneous findings among these studies.

In contrast to previous studies, our study included data about comorbidities among patients with herpes zoster. Associated chronic systemic diseases, including diabetes mellitus, chronic obstructive lung disease, autoimmune disease, congestive heart failure and cerebrovascular disease were consistent with previous epidemiologic studies conducted in Taiwan. ${ }^{1}$ Previous investigations that have focused on cancer risk among patients with herpes zoster have not provided such information. ${ }^{9-11}$ Diabetes mellitus ${ }^{20}$ and autoimmune disease ${ }^{21,22}$ have been reported to be risk factors for cancer. The immune-related comorbidity suggests a more impaired immune system, which may lead to a higher risk of subsequent cancer in patients with herpes zoster. A recent study conducted by Ho and colleagues ${ }^{13}$ in Taiwan found that the risk of cancer was increased after herpes zoster ophthalmicus. However, they did not provide comorbidity data in either the study or comparison groups, and they did not adjust for comorbidity. In our study, we found that, even among patients with immune-related comorbidity, the risk of cancer was not increased.

\section{Strengths and limitations}

The strengths of our study included its large nationwide population-based sample, the availability of data for patients with a wide range of demographic characteristics, and complete histories of the use of medical services for the included patients. The patients with herpes zoster received their diagnosis either in inpatient or outpatient clinics, which lessened the chance of selection bias arising from including only the most severely affected patients. The study population was well defined and followup was complete because our design relied on computerized registries with complete nationwide coverage. Therefore, our finding of no increased incidence of cancer among patients with herpes zoster is robust.

Several potential limitations should be noted. First, several risk factors for cancer, such as lifestyle, obesity, smoking, alcohol use and family history of cancer could not be assessed in our study. Second, the maximum length of follow-up in our cohort was 9 years (2000-2008); whether longer follow-up is required for the detection of some cancers among patients with herpes zoster 
requires further research. Finally, misclassification of diseases may occur when an administrative database is used. To minimize this issue, we identified cancer diagnoses using records from the Catastrophic Illness Patient Database, in which only patients with definite diagnoses were included. Herpes zoster is relatively straightforward to diagnose, and the validity of the coding for herpes zoster in administrative data is good. ${ }^{2}$

\section{Conclusion}

This population-based study shows that herpes zoster does not increase the overall risk of cancer in the general population. Among the subgroups stratified by sex, age and years of follow-up, there was no increased overall risk of cancer. These findings suggest that the extensive investigations for occult cancer at the time of diagnosis of herpes zoster or enhanced surveillance for cancer after such a diagnosis is unnecessary.

\section{References}

1. Jih JS, Chen YJ, Lin MW, et al. Epidemiological features and costs of herpes zoster in Taiwan: a national study 2000 to 2006 . Acta Derm Venereol 2009;89:612-6.

2. McDonald JR, Zeringue AL, Caplan L, et al. Herpes zoster risk factors in a national cohort of veterans with rheumatoid arthritis. Clin Infect Dis 2009;48:1364-71.

3. Thomas SL, Hall AJ. What does epidemiology tell us about risk factors for herpes zoster? Lancet Infect Dis 2004:4:26-33.

4. Wung PK, Holbrook JT, Hoffman GS, et al. Herpes zoster in immunocompromised patients: incidence, timing, and risk factors. Am J Med 2005;118:1416.

5. Smith JB, Fenske NA. Herpes zoster and internal malignancy. South Med J 1995;88:1089-92.

6. Goffinet DR, Glatstein EJ, Merigan TC. Herpes Zoster-Varicella infections and lymphoma. Ann Intern Med 1972;76:235-40.

7. Schimpff S, Serpick A, Stoler B, et al. Varicella-Zoster infection in patients with cancer. Ann Intern Med 1972;76:241-54.

8. Wyburn-Mason R. Malignant change arising in tissues affected by herpes. BMJ 1955;2:1106-9.

9. Ragozzino MW, Melton LJ III, Kurland LT, et al. Risk of cancer after herpes zoster: a population-based study. N Engl J Med 1982; 307:393-7.

10. Buntinx F, Wachana R, Bartholomeeusen S, et al. Is herpes zoster a marker for occult or subsequent malignancy? $\mathrm{Br} J$ Gen Pract 2005;55:102-7.

11. Sørensen HT, Olsen JH, Jepsen P, et al. The risk and prognosis of cancer after hospitalisation for herpes zoster: a populationbased follow-up study. Br J Cancer 2004;91:1275-9.

12. Yamamoto M, Mine H, Akazawa K, et al. Gastrointestinal cancer and herpes zoster in adults. Hepatogastroenterology 2003 50:1043-6.

13. Ho JD, Xirasagar S, Lin HC. Increased risk of a cancer diagnosis after herpes zoster ophthalmicus: a nationwide populationbased study. Ophthalmology 2011;118:1076-81.
14. Tsan YT, Lee CH, Wang JD, et al. Statins and the risk of hepatocellular carcinoma in patients with hepatitis B virus infection. $J$ Clin Oncol 2012; 30:623-30.

15. Yang YW, Chen YH, Wang KH, et al. Risk of herpes zoster among patients with chronic obstructive pulmonary disease: a population-based study. CMAJ 2011;183:E275-80.

16. Lin YT, Liu CJ, Chen TJ, et al. Pyogenic liver abscess as the initial manifestation of underlying hepatocellular carcinoma. Am J Med 2011;124:1158-64.

17. Chen YJ, Chang YT, Wang CB, et al. Malignancy in systemic lupus erythematosus: a nationwide cohort study in Taiwan. Am J Med 2010; 123:1150.e1-6.

18. Kang JH, Sheu JJ, Lin HC. Increased risk of Guillain-Barré syndrome following recent herpes zoster: a population-based study across Taiwan. Clin Infect Dis 2010;51:525-30

19. Kuo CC, Lee CT, Lee IM, et al. Risk of herpes zoster in patients treated with long-term hemodialysis: a matched cohort study. Am J Kidney Dis 2012;59:428-33.

20. Müssig K, Staiger H, Kantartzis K, et al. Type 2 diabetes mellitus and risk of malignancy: Is there a strategy to identify a subphenotype of patients with increased susceptibility to endogenous and exogenous hyperinsulinism? Diabet Med 2011;28:276-86.

21. Landgren AM, Landgren O, Gridley G, et al. Autoimmune disease and subsequent risk of developing alimentary tract cancers among 4.5 million US male veterans. Cancer 2011;117:1163-71.

22. Zintzaras E, Voulgarelis M, Moutsopoulos HM. The risk of lymphoma development in autoimmune diseases: A meta-analysis. Arch Intern Med 2005;165:2337-44.

Affiliations: From the Department of Medical Research and Education (Wang), Taipei Veterans General Hospital; the Division of Hematology and Oncology (Liu), Department of Medicine, Taipei Veterans General Hospital; the Cancer Center (Hu), Taipei Veterans General Hospital; the Department of Family Medicine (Chen), Taipei Veterans General Hospital; the Division of Infectious Diseases (Lin, Fung), Department of Medicine, Taipei Veterans General Hospital; the Department of Medicine (Hu, Chen), the Institute of Public Health (Liu), the Institute of Clinical Medicine (Lin), and the Institute of Emergency and Critical Care Medicine (Fung), School of Medicine, National Yang-Ming University, Taipei, Taiwan; and the Department of Internal Medicine (Liu), National Yang-Ming University Hospital, Yilan, Taiwan.

Contributors: Yu-Ping Wang and Chia-Jen Liu designed the study, analyzed the results of the data analysis, and drafted the manuscript. Yu-Ping Wang and Chia-Jen Liu equally contributed to this article. Yu-Wen Hu, Tzeng-Ji Chen and Chang-Phone Fung analyzed the data. Yi-Tsung Lin conceived, designed the study, interpreted the results of the data analysis, and drafted and revised the manuscript. All of the authors approved the final version submitted for publication.

Funding. This work was supported partly by grants from Taipei Veterans General Hospital (V101D-001-2)

Acknowledgements: This study is based in part on data from the National Health Insurance Research Database provided by the Bureau of National Health Insurance, Department of Health, and managed by the National Health Research Institutes. The interpretations and conclusions of this article do not represent those of the Bureau of National Health Insurance, Department of Health or National Health Research Institutes. 